Military Technical College Kobry El-Kobbah, Cairo, Egypt

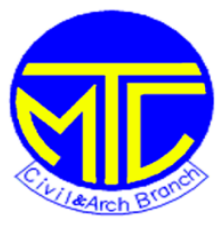

$12^{\text {th }}$ International Conference on Civil and Architecture Engineering ICCAE-12-2018

\title{
Daylighting Distribution Enhancement for Deep Office Spaces via Dynamic Louvers System, a case study in Cairo, Egypt.
}

\author{
Anwar Zayed ${ }^{1}$, Mahmoud Elkhateib ${ }^{1}$, Mohamed Mahdy ${ }^{1}$, Ibrahim Elwy ${ }^{1}$ \\ ${ }^{1}$ Military Technical College, Cairo, Egypt
}

\begin{abstract}
:
Integrating daylighting systems within building skin has grabbed numerous attentions, as a strategy to improve the natural lighting performance in deep office spaces.However, the stability and uniformity of daylight distribution throughout a day inside a building remain a challenge. The main concern of this work is to asses an advanced integrated daylighting system with automaticallycontrolled externallouvers throughout the year.A parametric design approach will facilitatea multistep comparison studyin order to identify the proper design for the system.A relatively uniform daylight range of 500-2000 lux was intended to be kept over the task-plans in the model of an $8 \mathrm{~m}$ deep office.
\end{abstract}

A simulation of an office building in Cairo was chosen asa case study, where it is south oriented with a prevailing condition of clear sky. The simulations will be conducted over four main periods (March, June, September, and December) to present the different seasons of the year.On the $21^{\text {st }}$ day of each chosen month,three differentpoints on time at $9 \mathrm{am}, 12 \mathrm{pm}$, and $3 \mathrm{pm}$ were utilized.

Wide ranges of angles were tested in order to explore the perfect inclination for the louvers in each period to take the most advantage from using natural daylight.Accordingly, three angles $\left(56^{\circ}, 59^{\circ}\right.$ and $62^{\circ}$ ) were selected per annum to fulfill the predefined criteria at the twelve times representing the four seasons (at $9.00 \mathrm{am}, 12.00 \mathrm{pm}$ and $3.00 \mathrm{pm}$ ) on the $21^{\text {st }}$ of March (vernal equinox); $21^{\text {st }}$ of June (summer solstice); $21^{\text {st }}$ of September (autumnal equinox) and 21 $\frac{\text { st }}{\text { of December (winter }}$ solstice). The aforementioned angles achieved the performance indicators targeted in the current study for daylight distribution.

This study is a part of ongoing research that aims to investigate the impact of the geometric configurations of louvers systems on improving the daylighting performance, in deep office buildings spaces in Egypt.Various software packageswere used in the work such as Rhino, Grasshopper and DIVA for modelling and simulating the generic office space.

\section{Introduction:}

Daylighting has great influence on buildings' occupants through its impact on the quality of space, which has direct and indirect effects on the well-being and productivity of the space users [1]. In comparison to the electric light, the daylighting has unique merits such as changing intensity, direction, timing, and providing an ideal colour which connects occupants to the surrounding conditions [2]. The general climate of Egypt (where the research took place) is characterized by the hot arid climate "BWh" according to Köppen classification [3, 4], and endowed with very high solar radiation intensity most of the year [5, 6]. 
As in the Egyptian solar Atlas (Fig. 1) the average direct normal solar radiation ranges between 2000-3200 kWh/m2/year, while the sunshine duration 9-11 h/day from North to South with very few cloudy days [7]. In such location, keeping adequate daylighting among the indoor spaces is quiet challenging, especially if noted that, most of the administrative buildings in Egypt tends to use the electric lighting during the working hours (8:00-18:00) due to poor daylighting distribution.

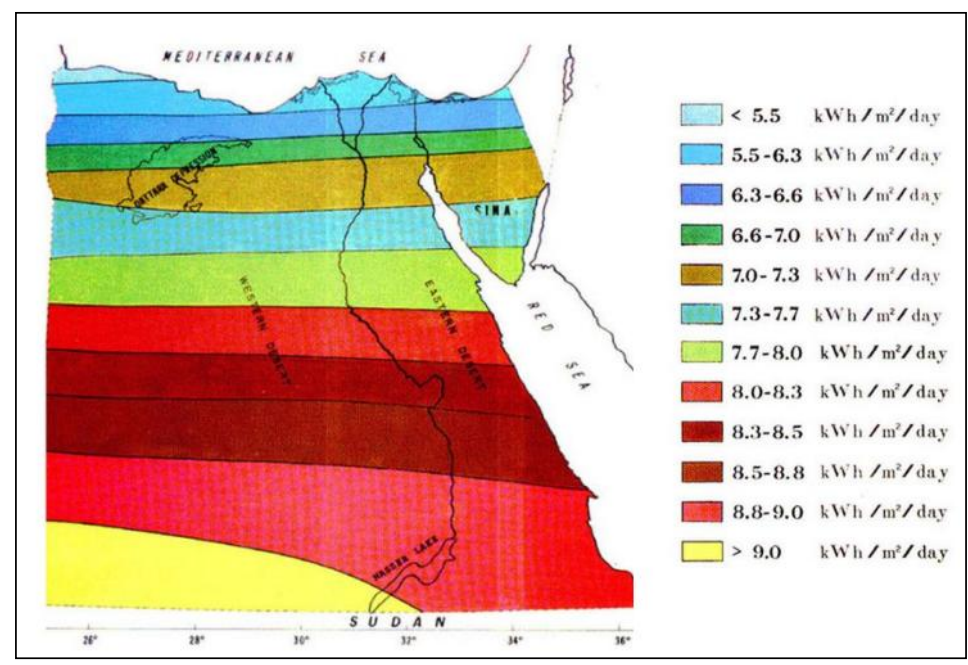

Figure 1: The annual average of the direct solar radiation in Egypt [7]

A study revealed that $80-90 \%$ of respondents believed thatwindowslouvers are used as a shading device to protect from excessive light more than thermal comfort and energy saving [8].

However, advanced louvers and other types of shading devices are controlled automatically[9] to maximize the benefits of daylight [10], save energy[11], provide visual comfort and improve the occupants' efficiency[12]. They can also be in different shapes and mechanisms according to facades' orientations and buildings' needs. It has been found that using automated louvers can reduce the users' behaviour of turning on the electric light, which can save electrical energy by up to $30 \%$ due to the utilization of daylight $[12,13]$.In similar cases, light reflectors (louvers) usually used to control the solar penetration into the space, and improves the daylighting distribution which will in turn decrease the visual discomfort via reducing the glare [14, 15].Such measures will contribute significantly in reducing the need for electric lighting, thus reducing the overall operative energy demands [16].Previous work in the same field discussed the use of either flat or curved section louvers to achieve better visual comfort while focusing on energy consumption [17-21].

From another point of view, the use of static identically shaped louvers has been argued by Thuot and Andersen [22] for emitting daylight at too high or downward angle at particular times of the day and year, causing glare under direct sunlight. However, their study did not consider the inclination angle to achieve daylight distribution along every single work-plane within the space.Consequently, in the current work, the dynamic use of flat louvers on a southern façade will tested to solve the aforementioned problems and improve performance in providing daylighting distribution, recently developed parametric software offers an efficient tool with a link to the popular software RADIANCNE, and therefore be able to control and optimize daylighting systems [23].

Overall, we can find that recent technologies software packages such as "Rhino" for modelling, "Grasshopper" as a parametric interface, and "DIVA" for daylight evaluation, of several architectural elements have clear influence on daylighting performance, while they are using different keys to achieving the goal of saving energy. 
More than 2000 simulations were conducted in order to determine the optimum inclination angels for the louvers to achieve the adequate daylighting distribution. The proper illuminance range were concluded according to the recommendations of: 1) the Illuminating Engineering Society of North America (IESNA), 2) The NRC Institute for Research in Construction and 3) the European Standard for Light and Lighting for Indoor Work Spaces [24-26].

\section{Methodology:}

Daylight illuminance will be measured using test points created via DIVA plug-in in Grasshopper; seventeen test points were selected according to the following:

1) Nine points on the commonly used taskplan $(T P) 76 \mathrm{cmabove}$ the floor.

2) Eight points for the daylight depth $(D D)$ were selected, the first point was located $0.5 \mathrm{~m}$ from the external wall, while the following points located with $1 \mathrm{~m}$ distance in between[27] as shown in fig.2.

For the simulations purpose, twelve times were selected to represent the four seasons of the year at three different points of time per day:

1) The three points of time areat $9.00 \mathrm{am}, 12.00 \mathrm{pm}$ and $3.00 \mathrm{pm}$.

2) The four selected days for presenting the different climatic periods are: the $21^{\mathrm{st}}$ of March (vernal equinox); $21^{\mathrm{st}}$ of June (summer solstice); $21^{\mathrm{st}}$ of September (autumnal equinox) and $21^{\text {st }}$ of December (winter solstice) $[15,28]$.

As revealed earlier, modelling of the office room will evolve through three phases via changing parameters of inclination angles, aiming to achieve better daylight distribution (See table 4).

Table 1: Phases Parameters

\begin{tabular}{|c|c|c|}
\hline No. & Simulation & Louvers design parameter in each phase \\
\hline Phase (1) Base Case & Base Case & No Louvers \\
\hline Phase (2) Exploration & $\begin{array}{c}\text { Flat Louvers } \\
\text { Narrow range }\end{array}$ & $\begin{array}{l}\text { With thickness } 1 \mathrm{~cm} \text { and depth of } 15 \mathrm{~cm} \\
\text { angle from }+90^{\circ} \text { to }-90^{\circ} \text { with steps of } 5^{\circ}\end{array}$ \\
\hline Phase (3) Refining & $\begin{array}{c}\text { Flat Louvers } \\
\text { Wide range }\end{array}$ & $\begin{array}{c}\text { With thickness } 1 \mathrm{~cm} \text { and depth of } 15 \mathrm{~cm} \\
\text { angle from }+75^{\circ} \text { to }-75^{\circ} \text { with steps of } 1^{\circ}\end{array}$ \\
\hline
\end{tabular}

- Phase (1)Base Case:the illuminance will be measured without louvers for all the 12 cases (3 point of time in the 4 different selected days).

- Phase (2) Exploration: the $15 \mathrm{~cm}$ width loverswith thickness of $1 \mathrm{~cm}$ were set to $0 \circ$ tilt angle in their straight shape, which is considered the best state of utilizing daylight [29].Putting in consideration the influence of specular and diffuse light coming from slats and sky dome [30],the louver controlled automatically.

In this phase the louvers will movewithin $5^{\circ}$ upor down from $-90^{\circ}$ to $+90^{\circ}$ and take the illuminance in the three times (per day) for the pre chosen four days in the year.Total of (444) simulations were conducted as follows: 37 angles * three/day *four days/year. Not all the tested angels achieved the acceptable range, which was the motivation to start Phase 3. 
- Phase (3)Refining: for more insight in the angles that can fulfil the requirements, new simulations were conducted starting from $-75^{\circ}$ to $+75^{\circ}$ with steps of one degree each to find the perfect inclination angles for the louvers. A sum of (151) angles * three/day * four days/year resulted in 1812 cases.

In order to carry out the results several packages were utilized such as:1) the parametric tool Grasshopper and its plug-in Diva[31]. Where Grasshopper itself is an algorithmic software used as a scripting language within Rhinoceros 3D computer graphics and computer aided design (CAD) [32], and it can deal with different parameters using specific formulas in order to define the model. These formulae appears as canvas connections, which can be amended and controlled parametrically at a convenient graphical interface [33].

Through utilizing the Genetic Algorithm (GA) as a part of the Grasshopper, the taskplan (76 cm) illuminance and daylight depth were optimized based on the predefined criteria shown in Fig. 2 and table 2 .

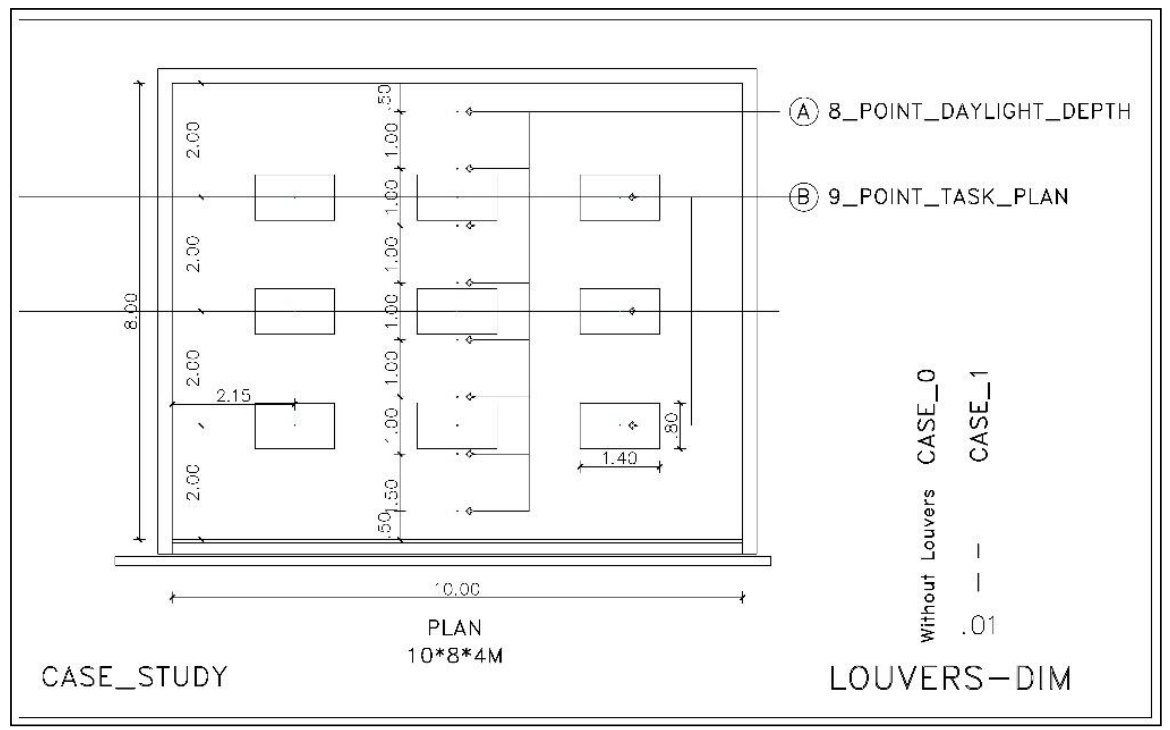

Figure 2: The case study diminution

Table 2: Illuminance criteria

\begin{tabular}{|c|c|c|}
\hline Indicator & Illuminance & Target \\
\hline 1 & Target for working plans & Should be between 500lux and 2000lux. \\
\hline 2 & Daylight depth(2x) & Should be between 300lux and 3000 lux. \\
\hline 3 & Contrast ratio & $1: 8$ \\
\hline
\end{tabular}

The selected case study is an office room in south oriented office building at Cairo - $\operatorname{Egypt}\left(30^{\circ} 2^{\prime \prime}\right.$ $\mathrm{N}, 31^{\circ} 14 " \mathrm{E}$ ), with hot arid conditionsand clear sky with sun most of the year[11, 34]. The (Cairo Intl Airport 623660 - ETMY)weather file with the EnergyPlus extension(.EPW)for Cairo Airport was used for the simulations using Grasshopper(See table 3). 


\begin{tabular}{|c|c|}
\hline Location & Cairo $\left(30^{\circ} 2^{\prime \prime} \mathrm{N}, 31^{\circ} 14^{\prime \prime} \mathrm{E}\right)$ \\
\hline Weather File & Cairo Intl Airport 623660(IWEC) \\
\hline Sky & Clear Sky with Sun \\
\hline
\end{tabular}

The office room is south oriented with $4 \mathrm{~m}$ height, $8 \mathrm{~m}$ depth and $10 \mathrm{~m}$ width. The slats (louvers) were set on a $100 \%$ WWR opening comprehensivelyfrom the floor to the ceiling as shown in fig.2. The walls were set to (Generic Interior 50\%) with 50\% reflectivity, the ceiling was set to white(Generic80\%) matt with $80 \%$ reflectivity, and the floor was set to tile (Tilefloor40\%) with $40 \%$ reflectivity. While the glazing was set to clear (Doublepane_clear_80\%) with $80 \%$ reflectivity, and the louvers were set to white (As ceiling painted80\%) with $80 \%$ reflectivity(See table 3 ).

Table 4: Model Material \& Reflectance

\begin{tabular}{|c|c|}
\hline Space & Reflectance \\
\hline Walls & GenericInterior_50\% \\
\hline Ceiling & Generic_80\% \\
\hline Floor & Tilefloor_40\% \\
\hline Glazing & Doublepane_clear_80\% \\
\hline Louvers & As ceiling painted_80\% \\
\hline
\end{tabular}

The impact of different inclination angles of louvers with the previously optimised inclination angels in the previous stage were evaluated to investigate the impact on the distribution of daylight inside office spaces. The design parameters of flat louvers were explained with different ranges.

\section{Results and Discussion:}

\section{1: Results:}

According to the simulation results for the base case scenario (Phase 1), all of the points of time are out of the illuminance acceptable range according to IESNA, NRC and the concerned European Standard[24-26]

In Phase two simulations, the results clarify that angles starting from (+90 to +75$)$ and (-90 to -75$)$ are failed to achieve the required predefined criteria for all the points of time(See table 2). Unlike wise, angles from +70 to -70 can fulfil the requirements in some of the points of time. Therefore, more detailed plan was created to refine the acceptable angles as follows in Phase 3.

At any time of the tested periods (Phase 3), the angles that fail to achieve the required levels of illuminance (500-2000 lux for taskplan and 300-3000 lux for daylight depth) will be neglected.The upcoming tables (5-8)will present the results of the hourly successful angels that achieved the aforementioned criteria listed in table 2.

a) Winter Solstice (21st of December) 
Table 5: Successful angels for winter solstice.

\begin{tabular}{|c|c|c|c|c|}
\hline & & $9 \mathrm{am}$ & $12 \mathrm{pm}$ & $15 \mathrm{pm}$ \\
\hline \multirow{2}{*}{ Taskplan } & + & $56,57,58,59,60,61,62,63,64$ & $62,63,64,65,66,67,68$ & $53,54,55,56,57,58,59,60,61,62$ \\
\cline { 2 - 5 } Daylight depth & - & $-75,-74,-73,-72$ & -- & $-74,-73,-72,-71,-70$ \\
\hline \multirow{3}{*}{ Tayy } & + & $51,52,53,54,55,56,57,58,59$, & $58,59,60,61,62,63,64,65$, & $49,50,51,52,53,54,55,56,57,58,59$, \\
& - & $60,61,62,63,64,65,66,67,68$ & $66,67,68,69,70,71,72,73$ & $60,61,62,63,64,65,66,67,68,69$ \\
\hline
\end{tabular}

b) Autumnal equinox (21st of September)

Table 6:Successful angels for autumnal equinox.

\begin{tabular}{|c|c|c|c|c|}
\hline & & $9 \mathrm{am}$ & $12 \mathrm{pm}$ & $15 \mathrm{pm}$ \\
\hline \multirow[t]{2}{*}{ Taskplan } & + & $\begin{array}{c}49,50,51,52,53,54,55,56,57 \\
58,59,60,61\end{array}$ & $\begin{array}{c}58,59,60,61,62,63,64,65 \\
66,67,68\end{array}$ & $\begin{array}{c}44,45,46,47,48,49,50,51,52,53,54 \\
55,56,57,58,59\end{array}$ \\
\hline & - & $-75,-74$ & -- & $-73,-72,-71,-70$ \\
\hline \multirow[t]{2}{*}{ Daylight depth } & + & $\begin{array}{c}39,40,41,42,43,44,45,46,47, \\
48,49,50,51,52,53,54,55,56, \\
57,58,59,60,61,62,63,64,65, \\
66,67,68\end{array}$ & $\begin{array}{l}50,51,52,53,54,55,56,57 \\
58,59,60,61,62,63,64,65 \\
\quad 66,67,68,69,70,71,72\end{array}$ & $\begin{array}{c}33,34,35,36,37,38,39,40,41,42,43, \\
44,45,46,47,48,49,50,51,52,53,54, \\
55,56,57,58,59,60,61,62,63,64,65, \\
66,67,68\end{array}$ \\
\hline & - & $-75,-74,-73,-72,-71,-70,-69$ & -- & $\begin{array}{c}-75,-74,-73,-72,-71,-70,-69,-68,-67, \\
-66,-65,-64\end{array}$ \\
\hline
\end{tabular}

c) Summer Solstice (21st of June)

Table 7:Successful angels for summer solstice.

\begin{tabular}{|c|c|c|c|c|}
\hline & & $9 \mathrm{am}$ & $12 \mathrm{pm}$ & $15 \mathrm{pm}$ \\
\hline \multirow[t]{2}{*}{ Taskplan } & + & zero to 56 & $\begin{array}{c}52,53,54,55,56,57,58,59 \\
60,61,62,63,64,65,66\end{array}$ & zero to 56 \\
\hline & - & -37 to zero & -- & -37 to zero \\
\hline \multirow[t]{2}{*}{ Daylight depth } & + & zero to 64 & $\begin{array}{c}31,32,33,34,35,36,37,38, \\
39,40,41,42,43,44,45,46, \\
47,48,49,50,51,52,53,54, \\
55,56,57,58,59,60,61,62, \\
63,64,65,66,67,68,71\end{array}$ & zero to 64 \\
\hline & - & -54 to zero & -- & -52 to zero \\
\hline
\end{tabular}

d) Vernal equinox (21st of March)

Table 8:Successful angels for vernal equinox

\begin{tabular}{|c|c|c|c|c|}
\hline & & $9 \mathrm{am}$ & $12 \mathrm{pm}$ & $15 \mathrm{pm}$ \\
\hline \multirow[t]{2}{*}{ Taskplan } & + & $\begin{array}{c}46,47,48,49,50,51,52,53,54 \\
55,56,57,58,59,60 \\
\end{array}$ & $\begin{array}{c}57,58,59,60,61,62,63,64, \\
65,66,6 \\
\end{array}$ & $\begin{array}{c}46,47,48,49,50,51,52,53,54,55,56, \\
57,58,59,60\end{array}$ \\
\hline & - & $-75,-74,-73,-72,-71$ & -- & $-75,-74,-73,-72$ \\
\hline \multirow[t]{2}{*}{ Daylight depth } & + & $\begin{array}{c}, 37,38,39,40,41,42,43,44, \\
45,46,47,48,49,50,51,52,53, \\
54,55,56,57,58,59,60,61,62, \\
63,64,65,66,67\end{array}$ & $\begin{array}{c}51,52,53,54,55,56,57,58, \\
59,60,61,62,63,64,65,66, \\
67,68,71,72\end{array}$ & $\begin{array}{c}37,38,39,40,41,42,43,44,45,46,47 \\
48,49,50,51,52,53,54,55,56,57,58 \\
59,60,61,62,63,64,65,66,67\end{array}$ \\
\hline & - & -- & -- & -- \\
\hline
\end{tabular}

The convergent inclination angles will be concluded as a result of analysing the comprehensiveexcel sheets, as follows.

\section{2: Discussions}

The following figures (3-6) represented the situation of each angle (including the common successful angles for each period) and if it can achieve the required rang of illuminance. Thatwill be presented through six columns in above of each angle in the $\mathrm{X}$-axis, while the $\mathrm{Y}$-axis presented the 
different points of time in each daylight metrics. The preferred angles that will success to complete the six columns above it will be shown below (i.e. achieved the required illuminance rang for the $T P$ and $D D$ in the same time for all the tested periods).

As shown in Fig. 3, only one angle $62^{\circ}$ will fulfil the requirements for the winter solstice, while angles $58^{\circ}$ and $59^{\circ}$ are the common angels for Autumnal Equinox as presented in fig. 4 . Fig. 5 shows the common angels for Summer Solstice $52^{\circ}, 53^{\circ}, 54^{\circ}, 55^{\circ}$ and $56^{\circ}$, and fig. 6 illustrates the group of angels that achieved the required criteria for Autumnal Equinox are $57^{\circ}, 58^{\circ}$ and $59^{\circ}$.

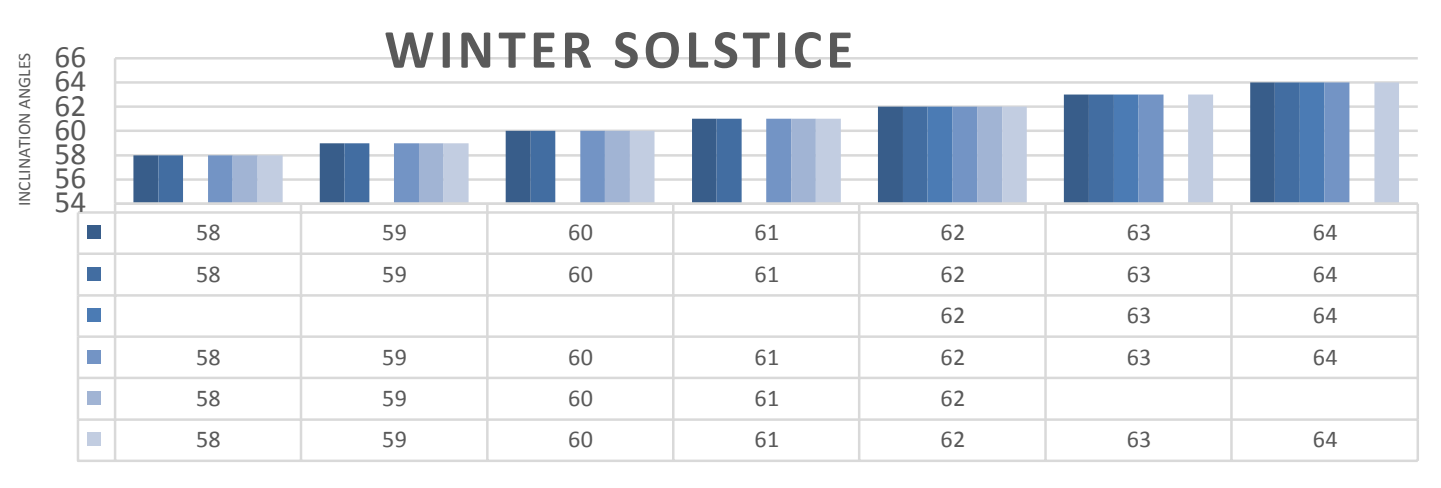

Figure 3: The Winter Solstice Inclination Angles convergent

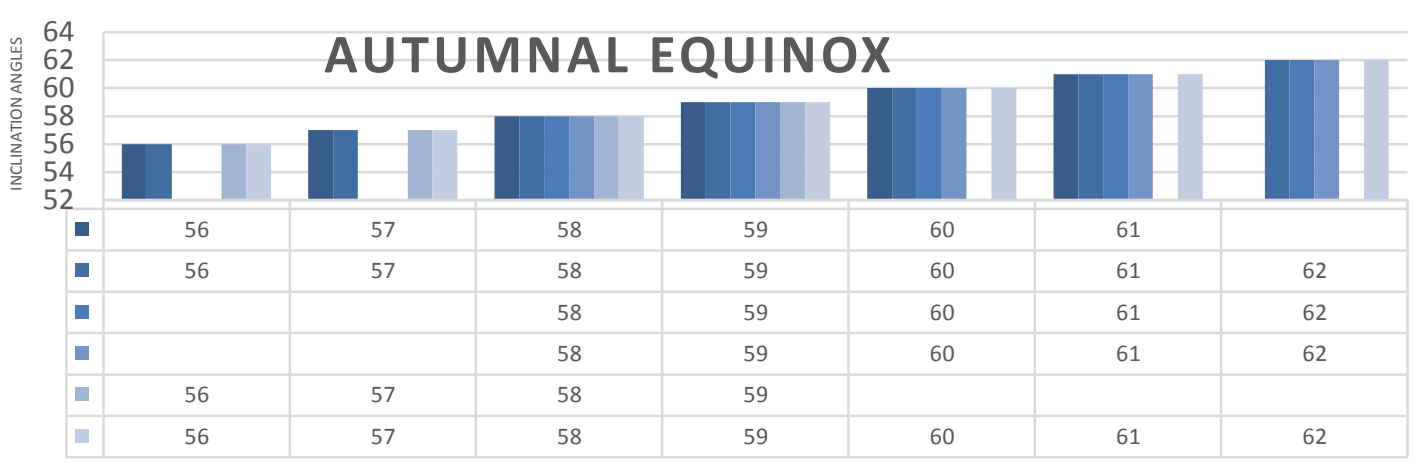

Figure 4: The Autumnal Equinox Inclination Angles convergent

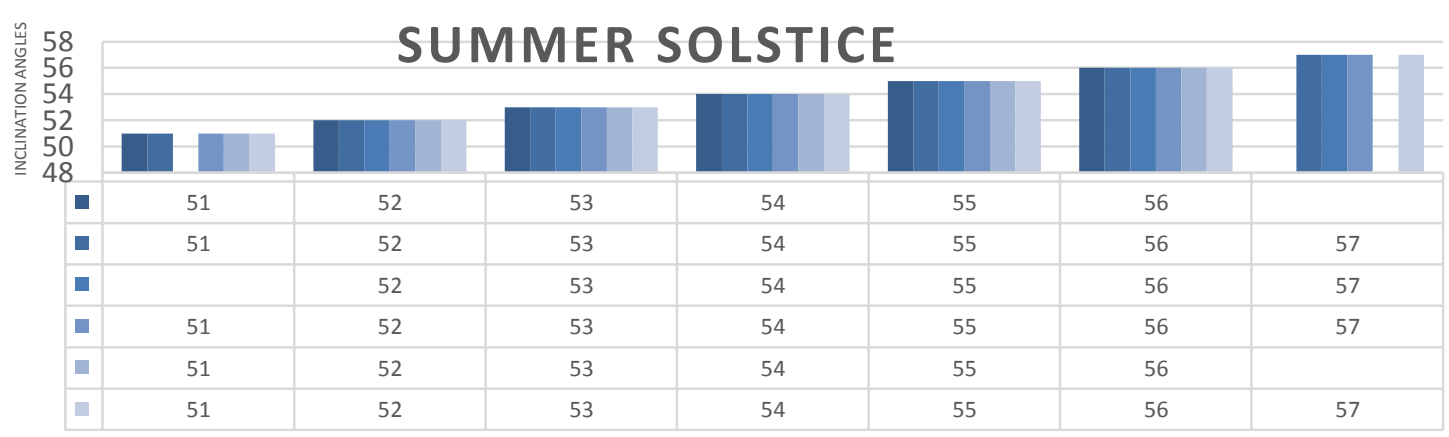

Figure 5: The Summer Solstice Inclination Angles convergent 


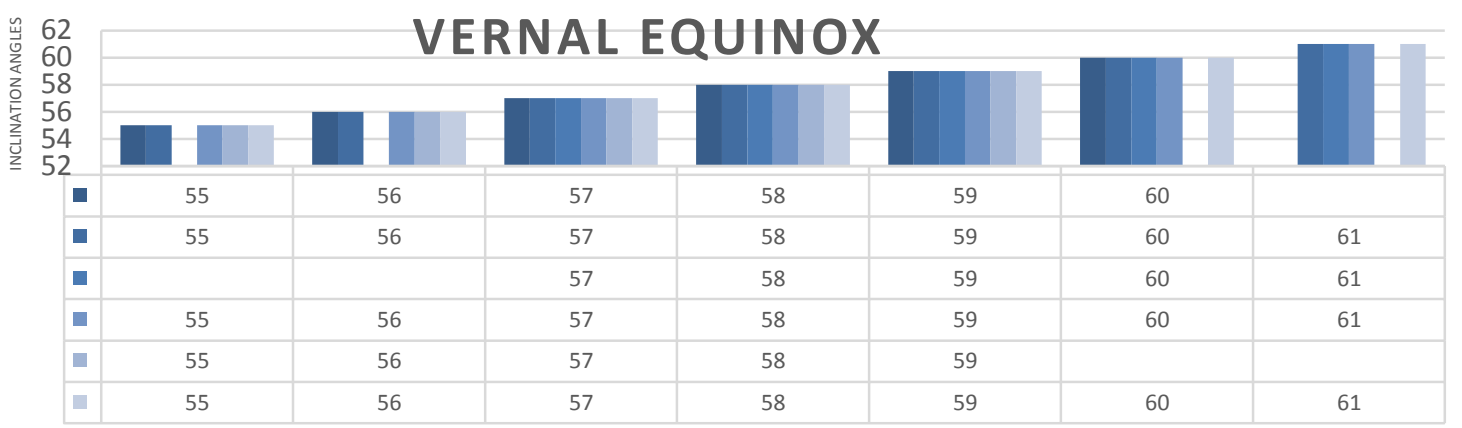

Figure 6: The Vernal Equinox Inclination Angles convergent

In order to differentiate between the various preferred angles more insight analysis will be heldusing Microsoft office (excel sheets), according to the illuminance levels over the TPand DDin all the different climatic periods at all points of time.

The more illuminance (beside the window) the more glare to produce, which willaffect the visual comfort of the occupants. Therefore, the angles with the lower illuminance levels (within the predefined criteria) will be preferred in order to avoid the inconvenience.

As examples for the aforementioned data analysis, the figures (7-9) below will clarify the illuminance levels over the $T P$ at $12 \mathrm{pm}$ that will reflect the common behavior of all the other cases. The nine points of $T P$ sensors (see fig.2) for each angle will be presented in the graph along the Xaxis, while the illuminance in Lux will appear in the Y-axis.

For the Autumnal equinox, fig.7shows that angle $59^{\circ}$ overcomes angle $58^{\circ}$ and achieved the optimum results for this climatic period. While the illuminance comparison between the five angles (52-53- 54- 55- 56) in the summer solstice resulted for the advantage of angle $\left(56^{\circ}\right)$ as shown in fig.8. Fig.9 represented the illuminance comparison between the three angles (57-58-59) at hour 12 $\mathrm{pm}$ for the taskplan and shows that angle $\left(59^{\circ}\right)$ is the best for good daylighting distribution in the vernal equinox. Whilst in the winter solstice, only angle $\left(62^{\circ}\right)$ has been achieved the requirements for the indoor illuminance over the differentdaylight metrics.

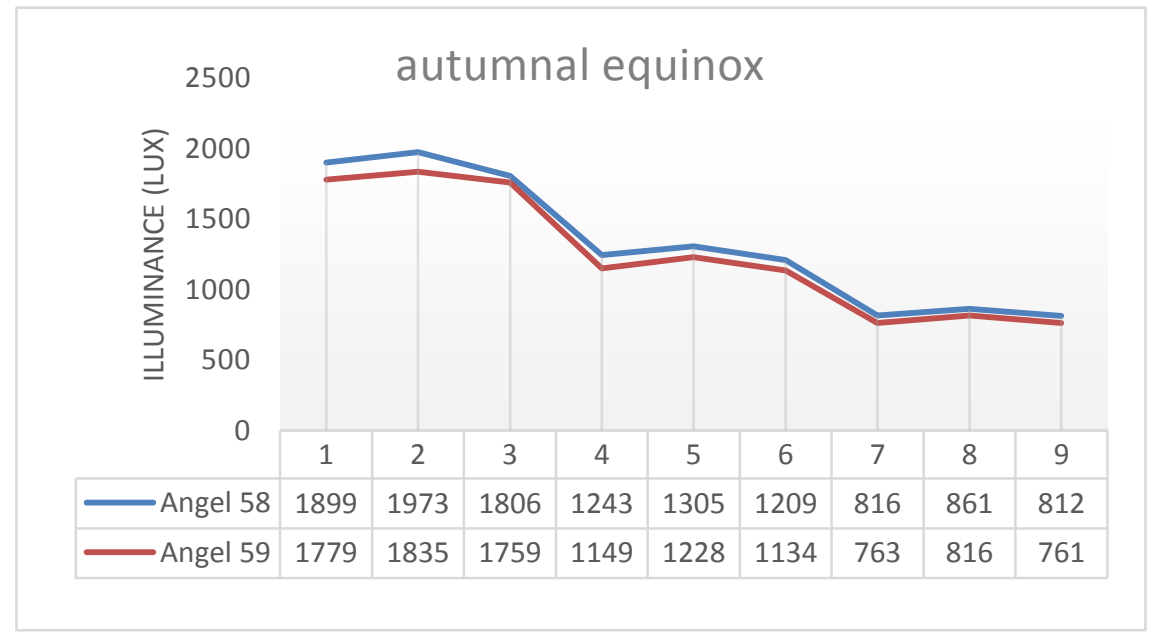

Figure 7: comparison between the angles on autumnal 


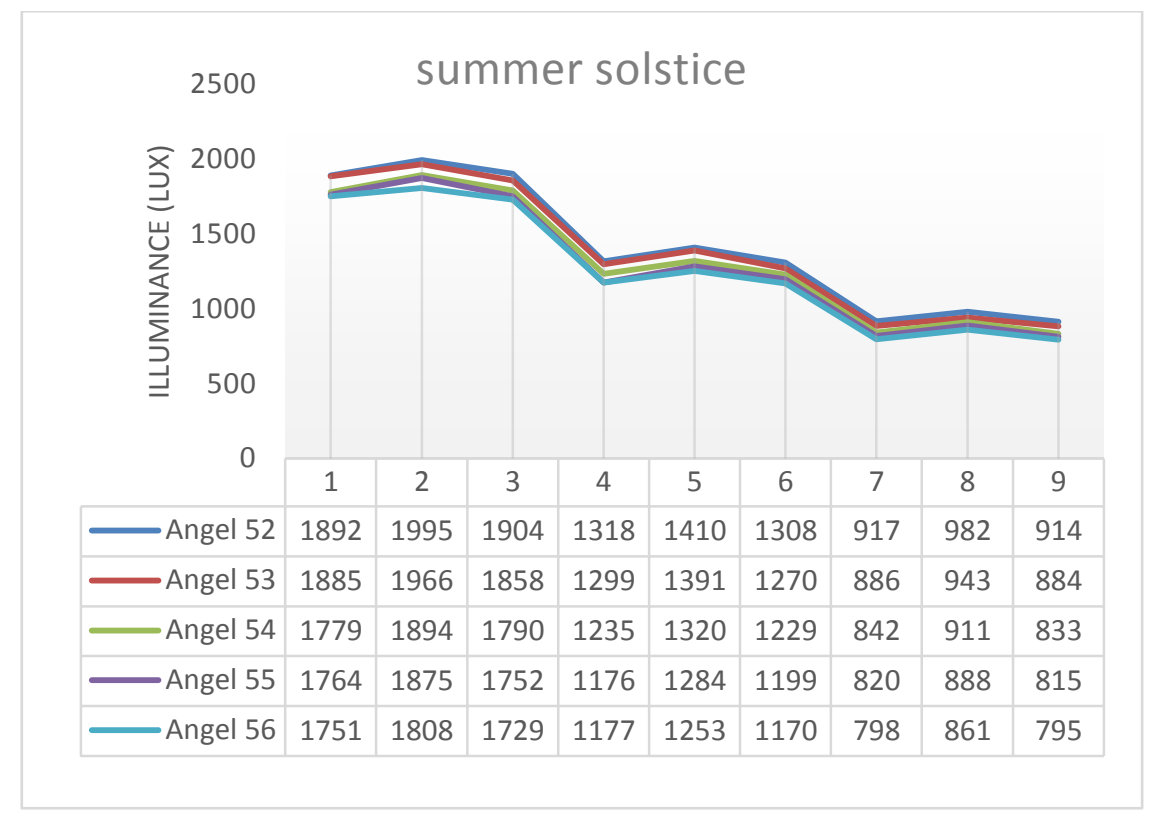

Figure 8: comparison between the angles on summer

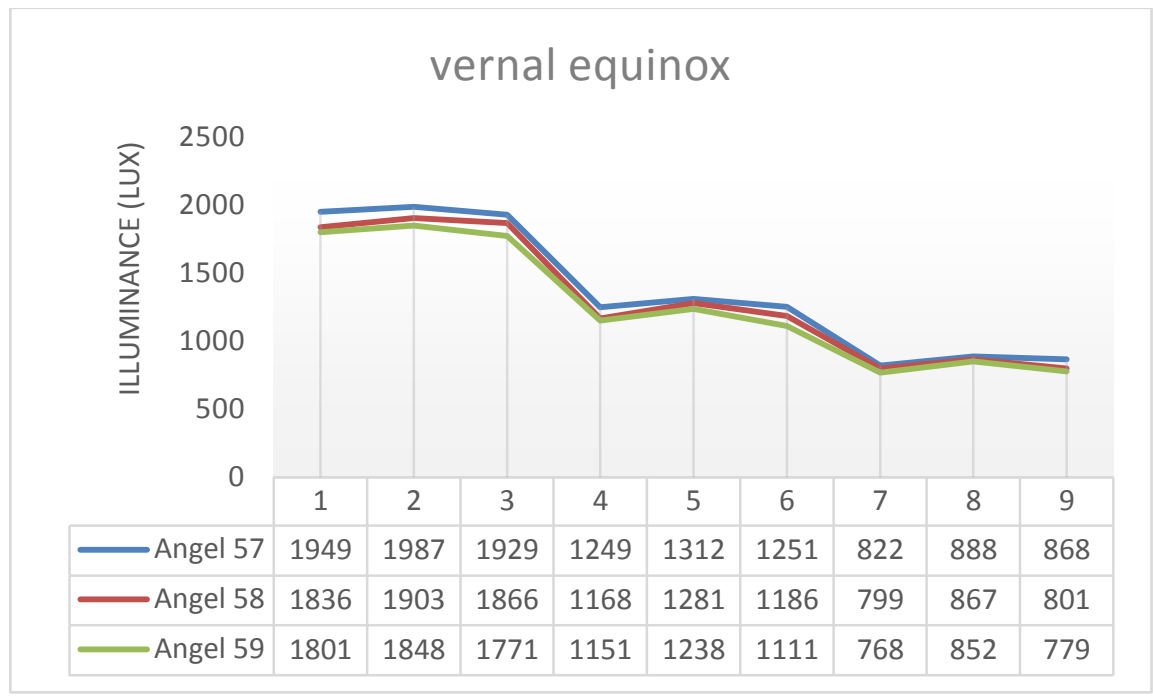

Figure 9: comparisonbetween the angles on vernal

\section{Conclusion}

Recent advancements in technology and computation tools afforded significant benefits for building skin design, in order to meet the altering users' preferences within the fluctuating environmental conditions.Thiswork has investigated the louversinclination angles parametrically, in order to achieve more homogeneouslydistribution for the natural daylight inside an office room in Cairo, Egypt. Additionally, illuminance ranges of 500-2000 lux for the task plans and 300-3000 lux for the daylight along the depthof the office are of the main targets for this work.

The intendedsolution has been achieved through a multistep comparison study employing parametric design tools for modelling(Rhino - Grasshopper), in addition to DIVA for the simulation processes.

The simulations were started withthe base case (Phase1 - no louver) to state the current conditions without any architectural treatments. The using of external automatedlouvers was examined in Phase 2 with the full range of angelsinclination with five degree steps form $\left(-90^{\circ}\right.$ to $\left.90^{\circ}\right)$, while the passed angles $\left(-75^{\circ}\right.$ to $\left.75^{\circ}\right)$ were refined and retested in Phase 3 by moving a one degree every timefor more accurate results. The angels $62^{\circ}$ for winter, $59^{\circ}$ for spring and autumn and $55^{\circ}$ for 
summerwere found to be the optimum angles to improve the daylight distribution into the inner office space and to fulfil the requirements according to the predefined criteria.

\section{References}

[1] N. V. Baker, A. Fanchiotti, and K. Steemers, Daylighting in architecture: a European reference book: Routledge, 2013.

[2] A. Vlachokostas and N. Madamopoulos, "Liquid filled prismatic louver fa\&\#x00E7; ade for enhanced daylighting in high-rise commercial buildings," Optics Express, vol. 23, pp. A805-A818, 2015/07/27 2015.

[3] M. Kottek, J. Grieser, C. Beck, B. Rudolf, and F. Rubel, "World Map of the Köppen-Geiger climate classification updated," Meteorologische Zeitschrift, vol. 15, pp. 259-263, 2006.

[4] M. C. Peel, B. L. Finlayson, and T. A. McMahon, "Updated world map of the Köppen-Geiger climate classification," Hydrology and Earth System Sciences Discussions vol. 4, pp. 439-473, 2007.

[5] G. M. S. S. r. o.-. Solar-GIS. (2013). Global Horizontal Irradiation - Africa and Middle East. Available: http://solargis.info/doc/_pics/freemaps/1000px/ghi/SolarGIS-Solar-map-Africa-and-Middle-East-en.png

[6] S. R. D.-. SODA. (2013). Maps of Irradiation - Africa - Photovoltaic Solar Electricity Potential. Available: http://www.soda-is.com/eng/map/maps for free.html\#pvgis-africa

[7] N. a. r. e. a. NREA, "New and renewable energy authority - Annual report - Egypt," New and renewable energy authority, Cairo 2011.

[8] K. Van Den Wymelenberg, "Patterns of occupant interaction with window blinds: A literature review," Energy and Buildings, vol. 51, pp. 165-176, 2012.

[9] M. Konstantoglou and A. Tsangrassoulis, "Dynamic operation of daylighting and shading systems: A literature review," Renewable and Sustainable Energy Reviews, vol. 60, pp. 268-283, 2016.

[10] S. Y. Koo, M. S. Yeo, and K. W. Kim, "Automated blind control to maximize the benefits of daylight in buildings," Building and Environment, vol. 45, pp. 1508-1520, 2010.

[11] M. V. Nielsen, S. Svendsen, and L. B. Jensen, "Quantifying the potential of automated dynamic solar shading in office buildings through integrated simulations of energy and daylight," Solar Energy, vol. 85, pp. 757-768, 2011.

[12] G. Y. Yun, H. Kim, and J. T. Kim, "Effects of occupancy and lighting use patterns on lighting energy consumption," Energy and Buildings, vol. 46, pp. 152-158, 2012.

[13] M. Boubekri, Daylighting, architecture and health: Routledge, 2008.

[14] A. Wagdy, A. Sherif, H. Sabry, R. Arafa, and I. Mashaly, "Daylighting simulation for the configuration of external sun-breakers on south oriented windows of hospital patient rooms under a clear desert sky," Solar Energy, vol. 149, pp. 164-175, 2017/06/01/ 2017.

[15] M. Elkhatieb and S. Sharples, "Climate Adaptive Building Shells for Office Buildings in Egypt: A Parametric and Algorithmic Daylight Tool," presented at the SBE16 Dubai, Dubai-UAE, 2016.

[16] A. Raimondi, D. Santucci, S. Bevilacqua, and A. Corso, "Daylight Autonomy as a Driver for Office Building Retrofitting," Energy Procedia, vol. 96, pp. 180-189, 2016/09/01/ 2016.

[17] M. El Sheikh and K. Kensek, "Intelligent skins: Daylight harvesting through dynamic light-deflection in office spaces," in ARCC 2011 Conference proceedings, 2011, pp. 293-304.

[18] D. Saelens, W. Parys, J. Roofthooft, and A. T. De la Torre, "Assessment of approaches for modeling louver shading devices in building energy simulation programs," Energy and Buildings, vol. 60, pp. 286$297,2013$.

[19] S. Vera, D. Uribe, W. Bustamante, and G. Molina, "Optimization of a fixed exterior complex fenestration system considering visual comfort and energy performance criteria," Building and Environment, vol. 113, pp. 163-174, 2017.

[20] K. Konis and E. S. Lee, "Measured daylighting potential of a static optical louver system under real sun and sky conditions," Building and Environment, vol. 92, pp. 347-359, 2015/10/01/ 2015.

[21] Z. L. Rogers, M. J. Holtz, C. M. Clevenger, and N. E. Digert, "Mini-optical light shelf daylighting system," ed: Google Patents, 2004.

[22] K. Thuot and M. Andersen, "A novel louver system for increasing daylight usage in buildings," in International Conference on Passive and Low Energy Architecture. Louvain-la-Neuve, 2011.

[23] A. Wagdy and F. Fathy, "A parametric approach for achieving optimum daylighting performance through solar screens in desert climates," Journal of Building Engineering, vol. 3, pp. 155-170, 2015/09/01/ 2015.

[24] M. S. Rea, "The IESNA lighting handbook: reference \& application," 2000.

[25] M. Frontczak and P. Wargocki, "Literature survey on how different factors influence human comfort in indoor environments," Building and Environment, vol. 46, pp. 922-937, 2011/04/01/ 2011.

[26] C. F. Reinhart, J. Mardaljevic, and Z. Rogers, "Dynamic daylight performance metrics for sustainable building design," Leukos, vol. 3, pp. 7-31, 2006. 
[27] Z. Staff, "The lighting handbook," Austria: Zumtobel, 2004.

[28] A. Eltaweel and S. Yuehong, "Using integrated parametric control to achieve better daylighting uniformity in an office room: A multi-Step comparison study," Energy and Buildings, vol. 152, pp. 137148, 2017/10/01/ 2017.

[29] J. Christoffersen, E. Petersen, and K. Johnsen, "An experimental evaluation of daylight systems and lighting control," in Right Light, 1997, pp. 245-254.

[30] Y.-C. Chan and A. Tzempelikos, "Efficient venetian blind control strategies considering daylight utilization and glare protection," Solar Energy, vol. 98, pp. 241-254, 2013.

[31] http://www.food4rhino.com/app/diva-rhino.

[32] https://www.rhino3d.com/.

[33] http://www.grasshopper3d.com/.

[34] M. C. Peel, B. L. Finlayson, and T. A. McMahon, "Updated world map of the Köppen-Geiger climate classification," Hydrology and earth system sciences discussions, vol. 4, pp. 439-473, 2007. 